\title{
The Relationship Between Spatial Access and Modern Contraceptive Use: Is Proximity to a Healthcare Facility a Determinant of Use Among Women in Kinshasa, DRC?
}

\section{Saleh Babazadeh ( $\nabla$ sbabazad@tulane.edu )}

Tulane University School of Public Health and Tropical Medicine https://orcid.org/0000-0002-2178$310 \mathrm{X}$

\section{Julie Hernandez}

Tulane University School of Public Health and Tropical Medicine

Philip Anglewicz

Johns Hopkins University Bloomberg School of Public Health

Jane T Bertrand

Tulane University School of Public Health and Tropical Medicine

\section{Research article}

Keywords: Relationship Between Spatial Access and Modern Contraceptive Use, Healthcare Facility, Women in Kinshasa, DRC

Posted Date: February 18th, 2020

DOI: https://doi.org/10.21203/rs.2.17656/v2

License: (c) (1) This work is licensed under a Creative Commons Attribution 4.0 International License.

Read Full License

Version of Record: A version of this preprint was published at Gates Open Research on May 13th, 2021. See the published version at https://doi.org/10.12688/gatesopenres.13229.1. 


\section{Abstract}

Background: Spatial access has a direct effect on health service utilization in many settings. While, all elements of access are usually affected by service delivery points and client characteristics. Distance to facility has proven to affect family planning service use in many Sub-Saharan countries. Studies show that women who reside closer to facilities offering family planning services are more likely to use modern contraceptives. However, researchers often test the theory of distance decay to observe any association between an increased distance of health facilities and health service utilization. This study to analyze the significance of proximity to family planning (FP) services, as well as service availability and quality of family planning services in Kinshasa. Methods: We used a pool of four rounds of facility- and populationbased survey data in Kinshasa. We tested if women who live closer to service delivery points with higher level of availability and quality are more likely to use modern contraceptives or less likely to have unmet need for contraceptive services. Results: Our findings show that living closer to an SDP is not a determinant of modern contraceptive use or having unmet need for FP services. Discussion: Lack of cognitive access, economic barriers, bypassing the closest facility, and sociocultural norms are among the strong barriers for women in Kinshasa not to use modern contraceptives. Our analysis shows that proximity to quality services does not necessarily result in increased FP use among women of reproductive age living in Kinshasa, thus suggesting that a bypass phenomenon may occur when obtaining modern contraceptive services. Conclusion: This study indicates that proximity to facilities does not necessarily equate proximity to methods, nor does it necessarily enable current users or women with an unmet need (potential contraceptive users) to easily obtain services for their method of choice. This study notes that other barriers to access may be substantial determinants of contraceptive use or unmet need. More research should be conducted that directly measures multidimensional components of access in order to interpret women's contraceptive seeking behaviors in urban areas of Sub-Saharan Africa.

\section{Background}

The FP2020 goal of "expanding access to family planning information, services, and supplies to an additional 120 million women and girls in the world's poorest countries by 2020", has been a driving force in the family planning community in recent years [1]. Access is usually affected by a range of both service delivery points and client characteristics [2]. It has been widely discussed in literature that spatial access has a direct effect on health service utilization [3-10].

In the context of family planning, spatial access is defined as the extent to which family planning service delivery and supply points are located so that a large proportion of the target population can reach them with an acceptable level of effort [11]. Researchers have applied various methods to measure spatial access $[2,4,12-14]$. Some have measured spatial access as an administrative indicator which is defined as the healthcare provider to population ratio within specific administrative units or other geographic areas [15-17]. This approach fails to recognize the fact that administrative boundaries are rarely the same as health system boundaries. It also does not take into account differences in population characteristics 
or demographics within a particular administrative boundary. Distance-based measures (compared to other measures such as population to facility ratios) have been increasingly used in recent years to assess spatial access. This has been made possible due to advancements in geographic information system (GIS) technology and improved availability of geographic data [18-20]. Although the proximity to a facility has been shown to have a significant role in health care utilization, meaningful measurement of this factor of accessibility remains challenging in the context of many low and middle-income countries $[9,21]$.

Literature on the importance of spatial access indicates that there is no consensus regarding the impact of distance on modern contraceptive use. Many studies have observed that the farther an individual lives from a health facility, the less likely they are to use contraceptive or other health services in that facility [3, $12,22-25]$. Where data is available, studies show that women who reside closer to facilities offering family planning (FP) services are more likely to use modern contraceptives. For example, Sultan et al. investigated service provision in rural Pakistan and found that women who lived within five kilometers of two community-based workers were significantly more likely to adopt a modern method of contraception than women who lived farther than 5 kilometers [25].

Contrarily, some studies have shown that distance to a facility has no significant effect on modern contraceptive use among women. One publication [26] observed the distance decay effect of family planning availability on modern contraceptive use among women in rural Bangladesh. Results from this study indicated that spatial access to selected facilities was not significantly correlated with contraceptive use [26]. Additionally, Achana and colleagues found that there was no linear relationship between distance to the closest health facility and modern contraceptive use among women in Upper East Ghana [27].

A literature review on spatial access to contraceptives also indicated that researchers often test the theory of distance decay to observe any association between an increased distance of health facilities and health service utilization. In other words, scientists have often tested the hypothesis that the farther a woman lives from a facility, the less likely she is to use contraception. The opposite hypothesis: the closer a woman lives to a facility, the more likely she uses contraceptive services, has not been widely investigated.

Furthermore, most studies assess proximity to health facilities as a driving factor for modern contraceptive use, without considering institution-specific characteristics, such as availability and quality of services. Although physical access to contraceptive services is necessary, it is not a sufficient metric alone for assessing the relationship between spatial access and contraceptive use. Numerous studies have found that quality of FP services is a crucial factor in women's uptake and continued use of family planning methods [28-32]. Moreover, despite the relative importance of proximity to a facility as a measure of access in low- and middle-income countries (LMIC), existing research is mostly aimed at evaluating access in rural areas $[9,31,33,34]$. There has been limited research on spatial access in large urban areas in LMIC, such as Kinshasa. 
This study aims to analyze the significance of proximity to family planning services, as well as service availability and quality of family planning services in Kinshasa. We test the effect of living closer to a facility on likelihood of using modern contraceptives in Kinshasa. Using data from Performance, Monitoring, and Accountability 2020 (PMA2020) surveys in Kinshasa, the present analysis aims to answer the question if proximity of women to facilities with better availability, service quality, choice of contraceptive methods either affects their contraceptive use or unmet need for family planning services, in Kinshasa, Democratic Republic of Congo (DRC). Addressing this question has important consequences for program design in Kinshasa, since it may indicate that spatial proximity, while necessary, is not a sufficient determinant of FP service use. Evidence from this study would contribute to informing policies that address gaps in expanding access to modern contraceptives among women in Kinshasa.

\section{Methods}

\section{A. Data}

This study uses the data from household and service delivery points (SDP) surveys conducted in Kinshasa, DRC, between 2014 and 2016 as part of four rounds (Round 2 to Round 5) of the Performance, Monitoring, and Accountability 2020 (PMA2020) project. PMA2020 is administered by the Kinshasa School of Public Health in collaboration with Tulane University. PMA2020 uses a smartphone-based data collection system (OpenDataKit) to collect data on key family planning indicators in Kinshasa.

PMA2020 includes both population- and facility-based surveys similar to Demographic and Health Survey (DHS) and Service Provision Assessment (SPA) surveys [35, 36]. However, in contrast to the DHS and SPA surveys, PMA2020 SDP allows for simultaneous collection of individual-level data in the same geographic location. Therefore, population and health service data are linked not only at the cluster level, but to specific facilities and individuals, through the collection of GPS coordinates. PMA2020 allows researchers to estimate and observe the association between the family planning service environment and use of contraceptives among women.

PMA2020 was conducted using a two-stage cluster sampling approach. In the first stage, the study team randomly selected 58 census enumeration areas (EA) using probability proportional to size (PPS) method within Kinshasa (out of a total of 335 EAs). For the second stage, data collectors listed all households in the selected EAs and randomly selected 33 households within each EA. All consenting women of reproductive age residing in selected households were interviewed using a questionnaire that included questions on demographics, fertility, contraceptive use, and other contraceptive-related topics.

The service delivery points (SDP) survey was administered among a maximum of six SDPs per EA: up to three public (government) and three private SDPs. The sampling strategy was different between public and private SDPs. For private facilities, resident enumerators (RE) first compiled a list of all private facilities within the EA. Private health facilities included faith-based SDPs, pharmacies and, private clinics, private hospitals, and other facilities with the capacity to provide contraceptive methods. From 
this list, supervisors randomly selected three for the RE to interview. For public SDPs, the survey team obtained a list of all public facilities from the DRC Ministry of Health that served each sampling EA catchment (regardless of whether the structure was actually in the EA). The list included lower-level health clinics, referral hospitals/health centers, and tertiary hospitals. The only tertiary hospital operating in Kinshasa was automatically included for all EA's, as there is only one tertiary hospital in the DRC and all EAs share it. All secondary hospitals were also included as long as they served the EA catchment population. If an EA had more than one lower-level facilities, one was randomly selected for the interview. Because EAs share public health facilities, not all EAs had six total SDPs in the sample. However, 38 out of 58 EAs had three or more private SDPs. The total number of SDPs per EA ranged between three and six.

\section{B. Spatial and Statistical Analysis:}

We evaluated two outcome variables in this study: modern contraceptive use and unmet need for family planning services. Modern contraceptive use was measured as a binary variable indicating whether or not a woman of reproductive age is currently using a modern method of contraception [37]. Unmet need for family planning was measured as a binary variable indicating whether a fertile woman, who desires to limit or postpone childbearing, is or is not currently using a contraceptive method [37].

Independent variables of interest in this study were constructed using the global positioning system (GPS) coordinates of SDPs and households. Proximity to SDPs that offered different levels of FP services and specific characteristics was used as a dependent variable to analyze the influence of SDPs location on use of modern contraceptive methods or experiencing an unmet need for such services. Proximity variables were developed through the creation of buffer zones around SDPs with these characteristics (such as offering long-acting reversible contraceptive [LARC], three or more, and five or more methods, experiencing no stock-outs, and requiring no FP patient fees). To investigate the effect of proximity to a facility on women's contraceptive behavior, we generated three different distance buffers ( 250 meters, 500 meters, and 1 kilometer) for all SDPs with specific characteristics.

Survey participants' residences and service delivery facilities coordinates were mapped for all four rounds of surveying. All spatial data was projected using the Universal Transverse Mercator (UTM ) zone 33s geo-coordinate system to accurately and systematically calculate proximity variables. We then created three buffer zones $(250 \mathrm{~m}, 500 \mathrm{~m}, 1000 \mathrm{~m})$ around each facility with specific characteristics.

We calculated the percentage of women using modern contraceptive(s) and the percentage of women with unmet need for family planning services in each buffer zone. In order to avoid double counting the SDPs in buffer zones that overlap each other, we used the dissolve function of the QGIS software to create a single buffer zone by dissolving the overlaid area of multiple overlapped buffer zones. This step provided the proportion of women using modern contraceptive and women with unmet need for FP within a certain distance of an SDP with specific characteristics. Since some women resided in multiple SDP 
buffer zones, dissolved buffers were used to prevent double counting of these individuals. Lastly, we assigned two measures to each SDP: the percentage of family planning users and percentage of women with unmet need within three increasing distances in each round of data collection.

We then tested if the prevalence of modern contraceptive users decreased as the distance to each SDP increased. The purpose of this analysis was to examine if proximity to SDPs with specific levels of FP services is a significant factor in determining modern contraceptive use, or having unmet need for family planning, among women in Kinshasa. We aimed to test if living closer to SDPs with specific characteristics increased the likelihood of women to use modern contraceptive or decreased the likelihood of having an unmet need for family planning. Based on this hypothesis, we expected to have a greater percentage of contraceptive users in radii closer to SDPs and a smaller proportion of users in radii farther from SDPs. Similarly, we expected to have a smaller percentage of women with unmet need in radii closer to SDPs and a greater proportion of women with unmet need in radii farther from SDPS.

We tested the proximity hypothesis with the arbitrarily selected buffers of $250 \mathrm{~m}, 500 \mathrm{~m}$ and $1 \mathrm{~km}$, as there is currently no evidence on the effect of distance on access to FP services in urban areas specifically.

The literature on access to healthcare in Sub-Saharan Africa mostly focuses individuals living in rural areas. There is not enough evidence to compare Kinshasa with other urban areas in Sub-Saharan Africa, as little data on the latter exists. Studies conducted in rural settings have shown that, on average, women tend to live further than $1 \mathrm{~km}$ from a health facility [38-41]. Kinshasa is a densely populated urban area with an estimated population of 12 million persons within a radius of 200 square miles (roughly as large as Chicago's urban area). Therefore, the households and SDPs are more concentrated and closer than what is observed in rural areas. Our initial analysis showed that, in all rounds of data collection, women on average live less than one kilometer of most SDPs in Kinshasa. We performed t-tests to verify if the proportion of modern contraceptive users in a $500 \mathrm{~m}$ radius of SDPs is smaller than a $250 \mathrm{~m}$ radius of SDPs. Similarly, the same analysis was used to test if the proportion of modern contraceptive users in $1000 \mathrm{~m}$ of SDPs is smaller than $500 \mathrm{~m}$ of SDPs.

\section{Results}

Our findings show that living closer to an SDP is not a determinant of modern contraceptive use or having unmet need for FP services. This result was observed with data collected from all rounds of surveying. Associations between distance to SDPs and changes in level of modern contraceptive use were insignificant.

Our analysis shows that, with increased distance to an SDP, the proportion of women using any modern contraceptive method does not decrease significantly. However, data collected from some rounds of surveying, illustrated a decrease in the percentage of women using a modern contraceptive method with an increase in distance from some SDPs. For example, in round 2 of PMA2020 in Kinshasa, the proportion of modern contraceptive users decreased from $21 \%$ to $16.3 \%$, when distance from an SDP that offered free services increased from $250 \mathrm{~m}$ to $1000 \mathrm{~m}$. Additionally, in round three of data, the 
proportion of modern contraceptive users decreased from $23.1 \%$ to $18.4 \%$, when distance from an SDP that provided at least 5 modern contraceptive methods was increased from $250 \mathrm{~m}$ to $1000 \mathrm{~m}$. However, as stated previously, these decreases in modern contraceptive use were not statistically significant.

Similarly, our findings present no significant difference between the proportion of women with unmet need for family planning and distances of $250 \mathrm{~m}, 500 \mathrm{~m}$, and $1000 \mathrm{~m}$ from an SDP that offers free services, or 5 or more modern contraceptive methods. We expected to find a higher proportion of women with unmet need for family planning in buffer zones further away from SDPs with preferable characteristics. Analysis of data collected in round 3 of PMA2020 shows that the proportion of women with unmet need for family planning increased from $15.0 \%$ in buffer zones $250 \mathrm{~m}$ from an SDP that provided at least five methods, to $18.2 \%$ in buffer zones $1000 \mathrm{~m}$ from an SDPs that provided at least five methods.

We evaluated several additional FP metrics and SDP characteristics to verify if any additional factors could be a determinant for modern contraceptive methods use women.

SDPs that had at least three or more methods in stock or five or more methods in stock were used to measure the availability of reliable FP services. The percentage of women that used modern contraceptives that lived within each buffer zone of and SDP that offered at least three or five methods did not significantly change. This suggests that living closer to a facility that has a larger range of available methods may not affect the likelihood of using family planning services.

PMA2020 results show that there is a growing tendency among women in the DRC to use long-acting reversible contraceptive (LARC) methods (specifically, the implant method) (PMA2020, 2018). We, therefore, used frequency and percentage of SDPs that had at least one long-acting reversible contraceptive (LARC) method as an indicator. Although the percentage of women using a modern contraceptive decreased with an increase in distance from an SDP with LARC methods in all rounds, this decline was not statistically significant. For instance, in round 2 , the proportion of women using modern contraceptives varied from $19.3 \%$ in areas $250 \mathrm{~m}$ from an SDP that provided LARC methods, to $18.4 \%$ in areas $1 \mathrm{~km}$ from an SDP that provided LARC methods. In Rounds 3 to 5, the proportion of modern contraceptive users varied from $19.3 \%, 23.3 \%$, and $22.0 \%$ in areas $250 \mathrm{~m}$ from an SDP to $17.9 \%, 22.4 \%$, and $20.3 \%$ in areas $1 \mathrm{~km}$ from the same SDPs, respectively (Tables $1-4$ ).

Table 1. Distribution of women living 250, 500, and 1000 meters from an SDP and corresponding contraceptive use and unmet need for FP services, PMA2020 survey round 2 


\begin{tabular}{|c|c|c|c|c|}
\hline $\mathrm{N}$ & $\begin{array}{c}\text { \% of women using a } \\
\text { modern contraceptive } \\
\text { method }\end{array}$ & $\begin{array}{c}\mathrm{P}- \\
\text { value* }\end{array}$ & $\begin{array}{c}\text { \% of women experiencing } \\
\text { an unmet need for FP } \\
\text { services }\end{array}$ & $\begin{array}{c}\mathrm{P}- \\
\text { value** }\end{array}$ \\
\hline
\end{tabular}

In $250 \mathrm{~m}$ radius of SDP that offers FP services

In $500 m$ radius of SDP that offers FP services

In $1 \mathrm{KM}$ radius of SDP that offers FP services

In $250 \mathrm{~m}$ radius of SDP that has $>3$ methods

In $500 m$ radius of SDP that has $>3$ methods

in $1 \mathrm{KM}$ radius of SDP that has $>3$ methods

In $250 \mathrm{~m}$ radius of SDP that has $>5$ methods

In $500 \mathrm{~m}$ radius of SDP that that has $>5$ methods

In $1 \mathrm{KM}$ radius of SDP that that has $>5$ methods

In $250 m$ radius of SDP with LARC methods

In $500 \mathrm{~m}$ radius of SDP with LARC methods

In $1 \mathrm{KM}$ radius of SDP with LARC methods

In $250 m$ radius of SDP open $>6$ days

In $500 m$ radius of SDP open $>6$ days

In $1 \mathrm{KM}$ radius of SDP open $>6$ days

In $250 m$ radius of SDP without stockout

In $500 \mathrm{~m}$ radius of SDP without stockout

In $1 \mathrm{KM}$ radius of SDP without stockout

In $250 m$ radius of SDP without fees

In $500 m$ radius of SDP without fees

In $1 \mathrm{KM}$ radius of SDP without fees
$1188 \quad 18.8 \%$

$18.0 \%$

$2453 \quad 18.5 \%$

$596 \quad 20.0 \%$

$1493 \quad 19.2 \%$

1.000

$19.0 \%$

$2138 \quad 18.3 \%$

$1.000 \quad 18.8 \%$

$14.8 \%$

$271 \quad 20.7 \%$

$796 \quad 20.9 \%$

1.000

$15.5 \%$

1.000

$16.4 \%$

$19.7 \%$

$1662 \quad 18.6 \%$

1.000

$19.0 \%$

$1.000 \quad 18.5 \%$

1.000

1.000

$2190 \quad 18.4 \%$

$964 \quad 17.7 \%$

$18.6 \%$

$1826 \quad 17.7 \%$

1.000

$18.7 \%$

1.000

$18.9 \%$

1.000

1.000

$2394 \quad 18.5 \%$

$945 \quad 19.0 \%$

$16.7 \%$

$1837 \quad 18.5 \%$

1.000

$17.6 \%$

1.000

$2291 \quad 18.7 \%$

1.000

$18.0 \%$

1.000

$267 \quad 21.0 \%$

$16.1 \%$

$708 \quad 16.9 \%$

1.000

$19.8 \%$

1.000

$1353 \quad 16.3 \%$

1.000

$20.9 \%$

1.000

1.000

1.000 
In $250 \mathrm{~m}$ radius of $\mathrm{HC}$ or hospital SDP

In $500 \mathrm{~m}$ radius of $\mathrm{HC}$ or hospital SDP

In $1 \mathrm{KM}$ radius of $\mathrm{HC}$ or hospital SDP
$111818.9 \%$

$1980 \quad 18.3 \%$

$2473 \quad 18.3 \%$
$17.7 \%$

$1.000 \quad 18.3 \%$

1.000

1.000

* t-test used to determine if the percentage in a larger radius is significantly lower than in a smaller radius **test-test used to determine if the percentage in a larger radius is significantly higher than in a smaller radius

On average more than $50 \%$ of SDPs were open seven days of the week. We limited our analysis to SDPs which were open every day of the week when measuring the availability of FP services and administrative access to services. In rounds 2 and 5, we found a decrease in the proportion of women using any modern contraceptive, as the distance from an SDP (that was open every day of the week) increased.

Table 2. Distribution of women living 250, 500, and 1000 meters from an SDP and corresponding contraceptive use and unmet need for FP services, PMA2020 survey round 3 


\begin{tabular}{|c|c|c|c|c|c|}
\hline & $\mathrm{N}$ & $\begin{array}{c}\% \text { of women using a } \\
\text { modern contraceptive } \\
\text { method }\end{array}$ & $\begin{array}{c}\text { P- } \\
\text { value* }\end{array}$ & $\begin{array}{c}\text { \% of women experiencing } \\
\text { an unmet need for FP } \\
\text { services }\end{array}$ & $\begin{array}{c}\mathrm{P}- \\
\text { value** }\end{array}$ \\
\hline $\begin{array}{l}\text { In } 250 \mathrm{~m} \text { radius of SDP } \\
\text { that offers FP }\end{array}$ & 1073 & $17.3 \%$ & & $18.2 \%$ & \\
\hline $\begin{array}{l}\text { In } 500 \mathrm{~m} \text { radius of SDP } \\
\text { that offers FP }\end{array}$ & 1960 & $17.4 \%$ & 1.000 & $19.2 \%$ & 1.000 \\
\hline $\begin{array}{l}\text { In } 1 \mathrm{KM} \text { radius of SDP } \\
\text { that offers FP }\end{array}$ & 2476 & $17.7 \%$ & 1.000 & $19.4 \%$ & 1.000 \\
\hline $\begin{array}{l}\text { In } 250 \mathrm{~m} \text { radius of SDP } \\
\text { that has }>3 \text { methods }\end{array}$ & 696 & $22.0 \%$ & & $15.2 \%$ & \\
\hline $\begin{array}{l}\text { In } 500 \mathrm{~m} \text { radius of SDP } \\
\text { that has }>3 \text { methods }\end{array}$ & 1609 & $21.6 \%$ & 1.000 & $16.1 \%$ & 1.000 \\
\hline $\begin{array}{l}\text { In } 1 \mathrm{KM} \text { radius of SDP } \\
\text { that has }>3 \text { methods }\end{array}$ & 2309 & $21.0 \%$ & 1.000 & $15.3 \%$ & 1.000 \\
\hline $\begin{array}{l}\text { In } 250 \mathrm{~m} \text { radius of SDP } \\
\text { that has }>5 \text { methods }\end{array}$ & 321 & $23.1 \%$ & & $15.0 \%$ & \\
\hline $\begin{array}{l}\text { In } 500 \mathrm{~m} \text { radius of SDP } \\
\text { that that has }>5 \text { methods }\end{array}$ & 911 & $21.0 \%$ & 1.000 & $16.2 \%$ & 1.000 \\
\hline $\begin{array}{l}\text { In } 1 \mathrm{KM} \text { radius of SDP } \\
\text { that that has }>5 \text { methods }\end{array}$ & 1737 & $18.4 \%$ & 1.000 & $18.2 \%$ & 1.000 \\
\hline $\begin{array}{l}\text { In } 250 m \text { radius of SDP } \\
\text { with LARC methods }\end{array}$ & 716 & $19.3 \%$ & & $18.0 \%$ & \\
\hline $\begin{array}{l}\text { In } 500 m \text { radius of SDP } \\
\text { with LARC methods }\end{array}$ & 1590 & $19.1 \%$ & 1.000 & $17.7 \%$ & 1.000 \\
\hline $\begin{array}{l}\text { In } 1 \mathrm{KM} \text { radius of SDP } \\
\text { with LARC methods }\end{array}$ & 2292 & $17.9 \%$ & 1.000 & $18.6 \%$ & 1.000 \\
\hline $\begin{array}{l}\text { In } 250 m \text { radius of SDP } \\
\text { open }>6 \text { days }\end{array}$ & 890 & $23.6 \%$ & & $15.3 \%$ & \\
\hline $\begin{array}{l}\text { In } 500 \mathrm{~m} \text { radius of SDP } \\
\text { open }>6 \text { days }\end{array}$ & 1824 & $24.8 \%$ & 1.000 & $17.3 \%$ & 1.000 \\
\hline $\begin{array}{l}\text { In } 1 \mathrm{KM} \text { radius of SDP } \\
\text { open }>6 \text { days }\end{array}$ & 2462 & $21.7 \%$ & 1.000 & $15.8 \%$ & 1.000 \\
\hline $\begin{array}{l}\text { In } 250 m \text { radius of SDP } \\
\text { without stockout }\end{array}$ & 660 & $17.6 \%$ & & $16.5 \%$ & \\
\hline $\begin{array}{l}\text { In } 500 m \text { radius of SDP } \\
\text { without stockout }\end{array}$ & 1322 & $17.8 \%$ & 1.000 & $18.8 \%$ & 1.000 \\
\hline $\begin{array}{l}\text { In } 1 \mathrm{KM} \text { radius of SDP } \\
\text { without stockout }\end{array}$ & 1977 & $18.1 \%$ & 1.000 & $19.0 \%$ & 1.000 \\
\hline $\begin{array}{l}\text { In } 250 \mathrm{~m} \text { radius of SDP } \\
\text { without fees }\end{array}$ & 164 & $14.0 \%$ & & $23.2 \%$ & \\
\hline $\begin{array}{l}\text { In } 500 m \text { radius of SDP } \\
\text { without fees }\end{array}$ & 497 & $15.7 \%$ & 1.000 & $23.9 \%$ & 1.000 \\
\hline $\begin{array}{l}\text { in } 1 \mathrm{KM} \text { radius of SDP } \\
\text { without fees }\end{array}$ & 1122 & $16.0 \%$ & 1.000 & $21.2 \%$ & 1.000 \\
\hline
\end{tabular}


In $250 \mathrm{~m}$ radius of $\mathrm{HC}$ or hospital SDP

In $500 \mathrm{~m}$ radius of $\mathrm{HC}$ or hospital SDP

In $1 \mathrm{KM}$ radius of $\mathrm{HC}$ or hospital SDP
$16.5 \%$

$16.5 \%$

$17.3 \%$
1.000

1.000
$18.7 \%$

$19.7 \%$

$19.6 \%$

* t-test used to determine if the percentage in a larger radius is significantly lower than in a smaller radius **test-test used to determine if the percentage in a larger radius is significantly higher than in a smaller radius

Stockouts are a significant barrier in accessing reproductive health services (Farmer et al. 2015) in many countries. We attempted to verify if proximity to a facility that had not experienced a stock-out in the last three months could be a determinant in using FP services. There was no significant difference in the proportion of women using a modern method in close proximity to an SDP that had not experienced a stockout when compared to those that were further away from an SDP that had not experienced a stockout. However, in Round 5, the percentage of women using a modern method decreased from $25.3 \%$ to $21.5 \%$ when proximity to an SDP that had not experienced a stockout increased from $250 \mathrm{~m}$ to $1 \mathrm{~km}$.

Facility services fees are a key financial barrier for women in accessing FP services (Bertrand et al. 1995; Choi et al. 2016). We tested if modern contraceptive use is higher among women that live closer to SDPs that provide services without fees. There was no significant difference between the proportion of women using modern contraceptives in any of the distance buffers of SDPs that provided services without fees.

Table 3. Distribution of women living 250, 500, and 1000 meters from an SDP and corresponding contraceptive use and unmet need for FP services, PMA2020 survey round 4 


\begin{tabular}{|c|c|c|c|c|c|}
\hline & $\mathrm{N}$ & $\begin{array}{c}\text { \% of women using a } \\
\text { modern contraceptive } \\
\text { method }\end{array}$ & $\begin{array}{c}\mathrm{P}- \\
\text { value* }\end{array}$ & $\begin{array}{c}\text { \% of women experiencing } \\
\text { an unmet need for FP } \\
\text { services }\end{array}$ & $\begin{array}{c}\mathrm{P}- \\
\text { value }^{* *}\end{array}$ \\
\hline $\begin{array}{l}\text { In } 250 \mathrm{~m} \text { radius of SDP } \\
\text { that offers FP }\end{array}$ & 1146 & $22.5 \%$ & & $15.4 \%$ & \\
\hline $\begin{array}{l}\text { In } 500 \mathrm{~m} \text { radius of SDP } \\
\text { that offers FP }\end{array}$ & 2005 & $20.9 \%$ & 1.000 & $15.5 \%$ & 1.000 \\
\hline $\begin{array}{l}\text { in } 1 \mathrm{KM} \text { radius of SDP } \\
\text { that offers } \mathrm{FP}\end{array}$ & 2481 & $21.4 \%$ & 1.000 & $15.7 \%$ & 1.000 \\
\hline $\begin{array}{l}\text { In } 250 \mathrm{~m} \text { radius of SDP } \\
\text { that has }>3 \text { methods }\end{array}$ & 689 & $22.2 \%$ & & $14.9 \%$ & \\
\hline $\begin{array}{l}\text { In } 500 \mathrm{~m} \text { radius of SDP } \\
\text { that has }>3 \text { methods }\end{array}$ & 1463 & $23.8 \%$ & 1.000 & $15.8 \%$ & 1.000 \\
\hline $\begin{array}{l}\text { in } 1 \mathrm{KM} \text { radius of SDP } \\
\text { that has }>3 \text { methods }\end{array}$ & 2159 & $22.5 \%$ & 1.000 & $15.2 \%$ & 1.000 \\
\hline $\begin{array}{l}\text { In } 250 \mathrm{~m} \text { radius of SDP } \\
\text { that has }>5 \text { methods }\end{array}$ & 417 & $23.0 \%$ & & $26.4 \%$ & \\
\hline $\begin{array}{l}\text { In } 500 \mathrm{~m} \text { radius of SDP } \\
\text { that that has }>5 \text { methods }\end{array}$ & 1049 & $21.4 \%$ & 1.000 & $21.0 \%$ & 1.000 \\
\hline $\begin{array}{l}\text { in } 1 \mathrm{KM} \text { radius of SDP } \\
\text { that that has }>5 \text { methods }\end{array}$ & 1775 & $20.1 \%$ & 1.000 & $21.5 \%$ & 1.000 \\
\hline $\begin{array}{l}\text { In } 250 \mathrm{~m} \text { radius of SDP } \\
\text { with LARC methods }\end{array}$ & 785 & $23.3 \%$ & & $22.8 \%$ & \\
\hline $\begin{array}{l}\text { In } 500 m \text { radius of SDP } \\
\text { with LARC methods }\end{array}$ & 1571 & $21.8 \%$ & 1.000 & $10.7 \%$ & 1.000 \\
\hline $\begin{array}{l}\text { in } 1 \mathrm{KM} \text { radius of SDP } \\
\text { with LARC methods }\end{array}$ & 2225 & $22.4 \%$ & 1.000 & $22.9 \%$ & 1.000 \\
\hline $\begin{array}{l}\text { In } 250 m \text { radius of SDP } \\
\text { open }>6 \text { days }\end{array}$ & 938 & $21.6 \%$ & & $17.0 \%$ & \\
\hline $\begin{array}{l}\text { In } 500 \mathrm{~m} \text { radius of SDP } \\
\text { open }>6 \text { days }\end{array}$ & 1788 & $20.4 \%$ & 1.000 & $16.2 \%$ & 1.000 \\
\hline $\begin{array}{l}\text { in } 1 \mathrm{KM} \text { radius of SDP } \\
\text { open }>6 \text { days }\end{array}$ & 2405 & $21.5 \%$ & 1.000 & $15.9 \%$ & 1.000 \\
\hline $\begin{array}{l}\text { In } 250 m \text { radius of SDP } \\
\text { without stockout }\end{array}$ & 685 & $17.2 \%$ & & $15.9 \%$ & \\
\hline $\begin{array}{l}\text { In } 500 m \text { radius of SDP } \\
\text { without stockout }\end{array}$ & 1226 & $18.4 \%$ & 1.000 & $15.8 \%$ & 1.000 \\
\hline $\begin{array}{l}\text { in } 1 \mathrm{KM} \text { radius of SDP } \\
\text { without stockout }\end{array}$ & 1877 & $19.8 \%$ & 1.000 & $15.7 \%$ & 1.000 \\
\hline $\begin{array}{l}\text { In } 250 \mathrm{~m} \text { radius of SDP } \\
\text { without fees }\end{array}$ & 356 & $16.9 \%$ & & $12.9 \%$ & \\
\hline $\begin{array}{l}\text { In } 500 m \text { radius of SDP } \\
\text { without fees }\end{array}$ & 793 & $20.1 \%$ & 1.000 & $18.2 \%$ & 1.000 \\
\hline $\begin{array}{l}\text { in } 1 \mathrm{KM} \text { radius of SDP } \\
\text { without fees }\end{array}$ & 1218 & $19.7 \%$ & 1.000 & $19.0 \%$ & 1.000 \\
\hline
\end{tabular}


In $250 \mathrm{~m}$ radius of $\mathrm{HC}$ or hospital SDP

In $500 \mathrm{~m}$ radius of $\mathrm{HC}$ or hospital SDP

in $1 \mathrm{KM}$ radius of $\mathrm{HC}$ or hospital SDP
1064

1904

2449
$22.6 \%$

$20.7 \%$

1.000

1.000

$21.5 \%$
$15.7 \%$

$15.5 \%$

* t-test used to determine if the percentage in a larger radius is significantly lower than in a smaller radius **test-test used to determine if the percentage in a larger radius is significantly higher than in a smaller radius

Our findings show that, although proximity to an SDP was not significantly associated with an unmet need for family planning services, lower percentages of women with unmet need were found in buffer zones closer to SDPs with certain characteristics. In Round 2, percentage of women with unmet need was lower among those $250 \mathrm{~m}$ from an SDP that had five or more methods in stock, had no stockouts in the last three months, or had no fees for services... In Round 3, percentage of women with unmet need was lower among those $250 \mathrm{~m}$ from an SDPs that had five or more methods in stock or had no stockouts in the last three months. In round 4, there percentage of women with unmet need was lower among those $250 \mathrm{~m}$ from an SDP that had no service fees.

Table 4. Distribution of women living 250, 500, and 1000 meters from an SDP and corresponding contraceptive use and unmet need for FP services, PMA2020 survey round 5 


\begin{tabular}{|c|c|c|c|c|c|}
\hline & $\mathrm{N}$ & $\begin{array}{c}\text { \% of women using a } \\
\text { modern contraceptive } \\
\text { method }\end{array}$ & $\begin{array}{c}\mathrm{P}- \\
\text { value* }\end{array}$ & $\begin{array}{c}\text { \% of women experiencing } \\
\text { an unmet need for FP } \\
\text { services }\end{array}$ & $\begin{array}{c}\mathrm{P}- \\
\text { value }^{* *}\end{array}$ \\
\hline $\begin{array}{l}\text { In } 250 \mathrm{~m} \text { radius of SDP } \\
\text { that offers FP }\end{array}$ & 1124 & $21.6 \%$ & & $13.5 \%$ & \\
\hline $\begin{array}{l}\text { In } 500 \mathrm{~m} \text { radius of SDP } \\
\text { that offers FP }\end{array}$ & 1929 & $20.7 \%$ & 1.000 & $14.7 \%$ & 1.000 \\
\hline $\begin{array}{l}\text { in } 1 \mathrm{KM} \text { radius of SDP } \\
\text { that offers } \mathrm{FP}\end{array}$ & 2393 & $20.2 \%$ & 1.000 & $14.9 \%$ & 1.000 \\
\hline $\begin{array}{l}\text { In } 250 \mathrm{~m} \text { radius of SDP } \\
\text { that has }>3 \text { methods }\end{array}$ & 732 & $21.2 \%$ & & $12.6 \%$ & \\
\hline $\begin{array}{l}\text { In } 500 \mathrm{~m} \text { radius of SDP } \\
\text { that has }>3 \text { methods }\end{array}$ & 1565 & $20.2 \%$ & 1.000 & $13.7 \%$ & 1.000 \\
\hline $\begin{array}{l}\text { in } 1 \mathrm{KM} \text { radius of SDP } \\
\text { that has }>3 \text { methods }\end{array}$ & 2232 & $20.3 \%$ & 1.000 & $14.3 \%$ & 1.000 \\
\hline $\begin{array}{l}\text { In } 250 \mathrm{~m} \text { radius of SDP } \\
\text { that has }>5 \text { methods }\end{array}$ & 417 & $18.9 \%$ & & $14.1 \%$ & \\
\hline $\begin{array}{l}\text { In } 500 \mathrm{~m} \text { radius of SDP } \\
\text { that that has }>5 \text { methods }\end{array}$ & 1049 & $20.4 \%$ & 1.000 & $14.7 \%$ & 1.000 \\
\hline $\begin{array}{l}\text { in } 1 \mathrm{KM} \text { radius of SDP } \\
\text { that that has }>5 \text { methods }\end{array}$ & 1775 & $21.7 \%$ & 1.000 & $15.4 \%$ & 1.000 \\
\hline $\begin{array}{l}\text { In } 250 \mathrm{~m} \text { radius of SDP } \\
\text { with LARC methods }\end{array}$ & 785 & $22.0 \%$ & & $12.2 \%$ & \\
\hline $\begin{array}{l}\text { In } 500 m \text { radius of SDP } \\
\text { with LARC methods }\end{array}$ & 1571 & $20.5 \%$ & 1.000 & $13.6 \%$ & 1.000 \\
\hline $\begin{array}{l}\text { in } 1 \mathrm{KM} \text { radius of SDP } \\
\text { with LARC methods }\end{array}$ & 2225 & $20.3 \%$ & 1.000 & $14.4 \%$ & 1.000 \\
\hline $\begin{array}{l}\text { In } 250 m \text { radius of SDP } \\
\text { open }>6 \text { days }\end{array}$ & 845 & $21.8 \%$ & & $20.7 \%$ & \\
\hline $\begin{array}{l}\text { In } 500 \mathrm{~m} \text { radius of SDP } \\
\text { open }>6 \text { days }\end{array}$ & 1612 & $22.6 \%$ & 1.000 & $13.5 \%$ & 1.000 \\
\hline $\begin{array}{l}\text { in } 1 \mathrm{KM} \text { radius of SDP } \\
\text { open }>6 \text { days }\end{array}$ & 2233 & $20.3 \%$ & 1.000 & $14.3 \%$ & 1.000 \\
\hline $\begin{array}{l}\text { In } 250 m \text { radius of SDP } \\
\text { without stockout }\end{array}$ & 522 & $25.3 \%$ & & $11.9 \%$ & \\
\hline $\begin{array}{l}\text { In } 500 m \text { radius of SDP } \\
\text { without stockout }\end{array}$ & 1088 & $23.9 \%$ & 1.000 & $13.8 \%$ & 1.000 \\
\hline $\begin{array}{l}\text { in } 1 \mathrm{KM} \text { radius of SDP } \\
\text { without stockout }\end{array}$ & 1820 & $21.5 \%$ & 1.000 & $15.4 \%$ & 1.000 \\
\hline $\begin{array}{l}\text { In } 250 \mathrm{~m} \text { radius of SDP } \\
\text { without fees }\end{array}$ & 356 & $21.3 \%$ & & $18.3 \%$ & \\
\hline $\begin{array}{l}\text { In } 500 m \text { radius of SDP } \\
\text { without fees }\end{array}$ & 793 & $20.1 \%$ & 1.000 & $18.2 \%$ & 0.908 \\
\hline $\begin{array}{l}\text { in } 1 \mathrm{KM} \text { radius of SDP } \\
\text { without fees }\end{array}$ & 1218 & $19.7 \%$ & 1.000 & $19.0 \%$ & 1.000 \\
\hline
\end{tabular}


In $250 \mathrm{~m}$ radius of $\mathrm{HC}$ or hospital SDP

In $500 \mathrm{~m}$ radius of $\mathrm{HC}$ or hospital SDP

in $1 \mathrm{KM}$ radius of $\mathrm{HC}$ or hospital SDP
1041

2350
1852

$22.0 \%$

$13.5 \%$

$20.8 \%$

1.000

$20.2 \%$

1.000
$14.8 \%$

$14.5 \%$

* t-test used to determine if the percentage in a larger radius is significantly lower than in a smaller radius **test-test used to determine if the percentage in a larger radius is significantly higher than in a smaller radius

\section{Discussion}

This study's aim was to assess the effect of proximity to family planning services on modern contraceptive use and unmet need for family planning among women living in Kinshasa. Our findings indicate that living in closer proximity to an SDP, even one with better availability and quality of FP services, does not increase the likelihood of modern contraceptive use among women in Kinshasa.

Many studies have analyzed physical access to a facility as a determinant of modern contraceptive use among women $[3,12,22,23,25]$. However, most of these studies have focused on the concept of distance decay, which measures how far living from an SDP decreases the likelihood of using FP or increases the likelihood of having unmet need. Few studies have tested the reverse hypothesis if living close to an SDP (even one with good quality services) changes women's likelihood of contraceptive use or having unmet need. In this study we hypothesized that facilities with better service availability and quality characteristics would have a higher proportion of contraceptive users and/or lower proportion of women with unmet need.

We discuss several probable explanations that could explain our results. For example, women in Kinshasa may not have the cognitive access required to utilize services in SDPs in close proximity of their residence. Cognitive access, as Bertrand et al discussed, is the extent to which potential clients are aware of the locations of service or supply points and of the services available at these locations (Bertrand et al 1995). Lack of knowledge regarding the existence of nearby SDPs would cause the unmet need for FP. This finding is consistent with a qualitative study performed in Kinshasa, where lack of knowledge about types and sources of contraceptives was among the reasons for not using contraceptive methods [42]. Another study conducted in Chad found that a correlation exists between wealth and the knowledge about the family planning service providers. (Gauthier and Wane, 2011).

Economic constraints could also be a barrier for women in accessing family planning services, even if they live in close proximity to an SDP. Gauthier and Wane found that individuals of lower socioeconomic status tend to seek care at lower quality facilities and bypass higher quality facilities because they cannot afford their services [43]. Moreover, in a study conducted in Kinshasa, Muanda et al. found that the cost of contraceptive services is an important barrier for women and a primary reason for non-use. For example, we know that the demand for implants among women in Kinshasa is increasing [44]. 
However, implants are one of the most expensive methods in Kinshasa and they are not available for free in most facilities. Thus, this economic barrier may be a reason why women in close proximity to SDPs refrain from using a modern method.

In addition, our findings confirm results of other studies conducted in the DRC and other sub-Saharan African countries in that they show that women prefer to bypass the closest facility to acquire their desired method from a facility farther away [43, 45-47]. These studies provide several reasons as to why individuals chose to bypass the closest facility. For example, this could be due to a lack of confidence in the availability and quality of service in the closest facility $[47,48]$. In a study in Egypt, Honge et al. found that that quality of family planning services available was a more prominent factor than the distance to the closest SDP in predicting use of IUDs among women [49]. Another study that evaluated bypassing behavior in Tanzania, showed that patients seek care at facilities that provide higher quality consultations, are staffed by more knowledgeable staff, and are better stocked with supplies [50].

Additionally, other factors influence service utilization at a facility, such as the need and women's intention to use family planning methods. Sociocultural norms can work as powerful motivators for women to bypass the closest facility to avoid encounters with family, neighbors, and friends. Women may also not use specific services despite the availability and quality of services if they do not intend to use modern contraception. Strong social norms that support large families are among the reasons cited as barriers to modern contraceptive use in Kinshasa [42]. These norms also might be a strong barrier for some women to use modern contraceptives. As Muanda et al. mentioned in their article, in strongly pronatalist African countries, socio-cultural norms often play a significant role in the decision-making process for contraception use [51]. They also discuss how cultural norms that support large families are the most difficult to address. In his article about high fertility norms in the DRC, Romanuik points to a mix of social, cultural and economic factors that encourage large families and the expectations from the husband's family for numerous children in return for the dowry paid for the woman [52]. Another study conducted in northern Ethiopia discussed the role of husbands' approval of contraceptive use and knowledge at least one contraceptive method as important factors that affect modern contraceptive use [53].

Although, studies have reported a significant correlation between distance to facilities and modern contraceptive use, especially in low and middle-income countries, $[3,12,22,23,25]$, the results of our analysis might be explained by other findings that indicate additional elements such as quality of services, economic access, and cultural factors that may influence contraceptive use [26, 27, 54, 55]. However, this analysis has several limitations and assumptions may influence our results. Our sampling approach limits the amount of data collected through facility surveys. The SDP survey collected data from 3-6 SDPs in each enumeration area. This number is a small fraction of all potential service delivery points and is not representative of the service and supply environment in Kinshasa. For a more accurate spatial analysis, a sample drawn from a census of all facilities would provide a more accurate measure of access to contraceptive methods. Whereas we know that women mat not necessarily use family planning services offered at the closest facility, data collection from a wider range of SDPs would shed 
light on other potential factors correlated with women's choice of facility for contraceptive services. The limited number of questions on the quality of available family planning services in the SDP survey also may also have influenced our findings. Although we assessed variables related to the quality of services in this analysis, the SDP survey does not provide the necessary information to comprehensively measure the quality of family planning services in the service delivery points in Kinshasa. For example, the PMA2020 SDP survey instrument does not capture any of the process factors of service quality (e.g. health provider's method of delivering services including interpersonal interaction with the client and technical competency), and outcomes (e.g. client's satisfaction of the family planning service) as discussed by Donbedian in his article about the quality of care [56].

Moreover, the distance calculated in this study is based on Euclidian distance measured between household location and the facility. Women who reside in a 1000-meter buffer of an SDP may need to travel a longer distance to reach the SDP. This approach usually underestimates the distance a woman should cross to reach the facility. Also, due to lack of information, we did not analyze other aspects of geographic distance, such as time travel and expense needed to reach each facility.

Another limitation of our study is our measurement of unmet need for family planning services, which was an analytically constructed variable. This means that there might be a discrepancy between having an unmet need for FP and the actual intention of women to seek contraceptive services [57]. However, some studies show that in West and Central Africa, more than half of women with an unmet need intend to use modern contraceptives in the future [58].

Service delivery structure in the DRC (similar to most LMICs) consists of fixed facilities, pharmacies, community-based distribution workers, unofficial drug shops and campaign distribution days. Almost one fifth of all women who using modern contraceptives acquired their methods from a source of distribution other than fixed service delivery points. These sources range from community health workers, medical students, mobile nurses, or other official or unofficial sources such as friend and family, bars and night clubs, religious organizations, and other sources [44,59-61]. The SDP survey did not capture information from the campaign distribution days, community-based distribution, and unofficial drug shops. In addition, the SDP data used in this study does not link women to the SDP that they actually visited and where they obtained a contraceptive method. Since the sampled SDPs were located in an urban area which has a large number of official and unofficial facilities where women could potentially receive family planning services, there is a considerable chance that women who received FP services bypassed the closest SDP, even if the SDP offered the desirable FP services.

In the current study, we aimed to investigate only the proximity to the facility as a determinant of using modern contraceptive or having unmet need for FP methods. We acknowledge that there are other factors that would affect one's contraceptive behavior or unmet need status. The current analysis aims to investigate prevalence rate of two contraceptive statuses (contraceptive user and with unmet need) in certain distances of SDPs regardless of other factors that may have played a role in defining such status. Hence, in this analysis we have not included the women's background characteristics as part of the 
equation. This approach is more reasonable in a setting that we have limited information on transportation types, roads, and costs of transportation.

Finally, the information gathered through the SDP survey was cross-sectional data and did not provide a comprehensive picture of the everchanging supply environment in Kinshasa. Most of the supply chain is managed by multiple donors and implementing organizations which procure and distribute commodities in parallel to national system supply chain channels [62]. This allows for a rapidly changing supply chain environment in which it is difficult to obtain comprehensive information regarding possible sources of contraceptive services.

\section{Conclusions}

This is the first study to use both population and facility-based data from the PMA2020 survey in Kinshasa to link key contraceptive use indicators and service availability at facilities. Our analysis shows that proximity to quality services does not necessarily result in increased FP use among women of reproductive age living in Kinshasa, thus suggesting that a bypass phenomenon may occur when obtaining modern contraceptive services. This study indicates that proximity to facilities does not necessarily equate proximity to methods, nor does it necessarily enable current users or women with an unmet need (potential contraceptive users) to easily obtain services for their method of choice. This study notes that other barriers to access may be substantial determinants of contraceptive use or unmet need. Further research should be conducted that directly measures multidimensional components of access in order to interpret women's contraceptive seeking behaviors in urban areas of Sub-Saharan Africa.

\section{Abbreviations}

DHS Demography and Health Survey

DRC Democratic Republic of Congo

EA Enumeration Area

FP Family Planning

GIS Geographic Information System

GPS Global Positioning System

LARC Long-Acting Reversible Contraceptive

LMIC Low- and Middle-Income Country

PMA2020 Performance, Monitoring, and Accountability

PPS Probability Proportional to Size 
SPA

Service Provision Assessment

UTM

Universal Transverse Mercator

\section{Declarations}

\section{Ethics approval and consent to participate}

Institutional Review Board (IRB)/Ethics Committee approval was obtained by Tulane Institutional Review Board (\#492318), as well as by the Ethics Committee of the Kinshasa SPH (ESP/CE/043/11 and $\mathrm{ESP} / \mathrm{CE} / 072 / 13)$.

\section{Consent for publication}

Not applicable

\section{Competing interests}

The authors declare that they have no competing interests.

\section{Funding:}

PMA2020 was supported by the Bill \& Melinda Gates Foundation, Seattle, WA; under grant \#OPP1079004.

\section{Authors' contribution:}

SB and $\mathrm{JH}$ developed and conceptualized the approach. SB condcuted the analysis and led the writing the manuscript. JH, JB, and PA provided the edits. All aithors read and approved the final manuscript.

\section{Acknowledgements:}

Not applicable

\section{Availability of data and materials}

The dataset(s) used for the current study are available in the IPUMS PMA repository via the following link: https://pma.ipums.org/pma/

The analyzed data in this study is availabel upon request from the corresponding author.

\section{References}


1. FP2020: Progress report 2012-2013: Partnership in action. In.; 2013.

2. Goodman DC, Klerman LV, Johnson KA, Chang C-h, Marth N: Geographic access to family planning facilities and the risk of unintended and teenage pregnancy. Maternal and Child Health Journal 2007, 11(2):145-152.

3. Tsui AO, Hogan DP, Teachman JD, Welti-Chanes C: Community availability of contraceptives and family limitation. Demography 1981, 18(4):615-625.

4. Arcury TA, Preisser JS, Gesler WM, Powers JM: Access to transportation and health care utilization in a rural region. The Journal of Rural Health 2005, 21(1):31-38.

5. Baume C, Helitzer D, Kachur SP: Patterns of care for childhood malaria in Zambia. Social science \& medicine 2000, 51(10):1491-1503.

6. Buor D: Analysing the primacy of distance in the utilization of health services in the Ahafo-Ano South district, Ghana. The International journal of health planning and management 2003, 18(4):293-311.

7. Gething PW, Noor AM, Zurovac D, Atkinson PM, Hay SI, Nixon MS, Snow RW: Empirical modelling of government health service use by children with fevers in Kenya. Acta tropica 2004, 91(3):227-237.

8. Joseph AE, Phillips DR: Accessibility and utilization: geographical perspectives on health care delivery: Sage; 1984.

9. Tanser F, Gijsbertsen B, Herbst K: Modelling and understanding primary health care accessibility and utilization in rural South Africa: an exploration using a geographical information system. Social science \& medicine 2006, 63(3):691-705.

10. Tsoka J, Le Sueur D: Using GIS to measure geographical accessibility to primary health care in rural South Africa: research in action. South African Journal of Science 2004, 100(7-8):329-330.

11. Bertrand JT, Hardee K, Magnani RJ, Angle MA: Access, Quality Of Care and Medical Barriers In Family Planning Programs. International Family Planning Perspectives 1995, 21(2):64-74.

12. Stock R: Distance and the utilization of health facilities in rural Nigeria. Social science \& medicine 1983, 17(9):563-570.

13. McGrail MR, Humphreys JS: Measuring spatial accessibility to primary care in rural areas: improving the effectiveness of the two-step floating catchment area method. Applied Geography 2009, 29(4):533-541.

14. Yao J, Murray AT, Agadjanian V: A geographical perspective on access to sexual and reproductive health care for women in rural Africa. Social Science \& Medicine 2013, 96:60-68.

15. Guagliardo MF: Spatial accessibility of primary care: concepts, methods and challenges. International journal of health geographics 2004, 3(1):3.

16. Wang W, Wang S, Pullum T, Ametepi P: How family planning supply and the service environment affect contraceptive use: Findings from four East African countries. 2012.

17. Hernandez JH, Akilimali P, Kayembe P, Dikamba N, Bertrand $\mathrm{J}$ : The value of spatial analysis for tracking supply for family planning: the case of Kinshasa, DRC. Health Policy and Planning 2016:czw036. 
18. Higgs G: A Literature Review of the Use of GIS-Based Measures of Access to Health Care Services. Health Serv Outcomes Res Method 2004, 5(2):119-139.

19. Musa GJ, Chiang PH, Sylk T, Bavley R, Keating W, Lakew B, Tsou HC, Hoven CW: Use of GIS Mapping as a Public Health Tool-From Cholera to Cancer. In: Health Serv Insights. Volume 6, edn.; 2013: 111116.

20. Cromley E, McLafferty S: GIS and public health. 2002. New York: Guilford 2002.

21. Bertrand J: Locating family planning services and organizing to increase access in Kinshasa, DRC. In: 142nd APHA Annual Meeting and Exposition (November 15-November 19, 2014): 2014: APHA; 2014.

22. Tsui AO, Hogan DP, Welti-Chanes C, Teachman JD: Contraceptive availability differentials in use and fertility. Stud Fam Plann 1981, 12(11):381-393.

23. Entwisle B, Rindfuss RR, Walsh SJ, Evans TP, Curran SR: Geographic information systems, spatial network analysis, and contraceptive choice. Demography 1997, 34(2):171-187.

24. Dubale T, Mariam DH: Determinants of conventional health service utilization among pastoralists in northeast Ethiopia. Ethiopian Journal of Health Development 2007, 21(2):142-147.

25. Sultan M, Cleland JG, Ali MM: Assessment of a new approach to family planning services in rural Pakistan. American journal of public health 2002, 92(7):1168-1172.

26. Paul BK: Family planning availability and contraceptive use in rural Bangladesh: An examination of the distance decay effect. Socio-Economic Planning Sciences 1991, 25(4):269-282.

27. Achana FS, Bawah AA, Jackson EF, Welaga P, Awine T, Asuo-Mante E, Oduro A, Awoonor-Williams JK, Phillips JF: Spatial and socio-demographic determinants of contraceptive use in the Upper East region of Ghana. Reproductive health 2015, 12(1):1.

28. Jain AK: Fertility reduction and the quality of family planning services. Studies in family planning 1989:1-16.

29. Mensch $B$, Arends-Kuenning $M$, Jain A: The impact of the quality of family planning services on contraceptive use in Peru. Studies in family Planning 1996:59-75.

30. Bollen KA, Guilkey DK, Mroz TA: Binary outcomes and endogenous explanatory variables: tests and solutions with an application to the demand for contraceptive use in Tunisia. Demography 1995, 32(1):111-131.

31. Magnani RJ, Hotchkiss DR, Florence CS, Shafer LA: The impact of the family planning supply environment on contraceptive intentions and use in Morocco. Studies in family planning 1999, 30(2):120-132.

32. Mariko M: Quality of care and the demand for health services in Bamako, Mali: the specific roles of structural, process, and outcome components. Social Science \& Medicine 2003, 56(6):1183-1196.

33. Noor A, Zurovac D, Hay S, Ochola S, Snow R: Defining equity in physical access to clinical services using geographical information systems as part of malaria planning and monitoring in Kenya. Tropical Medicine \& International Health 2003, 8(10):917-926. 
34. Shiferaw S, Spigt M, Seme A, Amogne A, Skrøvseth S, Desta S, Radloff S, Tsui A, GeertJan D: Does proximity of women to facilities with better choice of contraceptives affect their contraceptive utilization in rural Ethiopia? PloS one 2017, 12(11):e0187311.

35. Female Questionnaire [https://www.pmadata.org/sites/default/files/2019-11/PMA-FemaleQuestionnaire-English-2019-10-10.pdf]

36. Service Deliver Point (SDP) Questionnaire [https://www.pmadata.org/sites/default/files/201911/PMA-SDP-Questionnaire-English-2019-10-10.pdf]

37. MEASURE Evaluation, [https://www.measureevaluation.org/about/introduction]

38. De Allegri M, Ridde V, Louis VR, Sarker M, Tiendrebéogo J, Yé M, Müller O, Jahn A: Determinants of utilisation of maternal care services after the reduction of user fees: a case study from rural Burkina Faso. Health policy 2011, 99(3):210-218.

39. Johnson FA, Frempong-Ainguah F, Matthews Z, Harfoot AJ, Nyarko P, Baschieri A, Gething PW, Falkingham J, Atkinson PM: Evaluating the impact of the community-based health planning and services initiative on uptake of skilled birth care in Ghana. PLoS One 2015, 10(3):e0120556.

40. Dickson KS, Adde KS, Amu H: What influences where they give birth? Determinants of place of delivery among women in rural Ghana. International journal of reproductive medicine 2016, 2016.

41. Nakua EK, Sevugu JT, Dzomeku VM, Otupiri E, Lipkovich HR, Owusu-Dabo E: Home birth without skilled attendants despite millennium villages project intervention in Ghana: insight from a survey of women's perceptions of skilled obstetric care. BMC pregnancy and childbirth 2015, 15(1):243.

42. Muanda M, Ndongo PG, Taub LD, Bertrand JT: Barriers to modern contraceptive use in Kinshasa, DRC. PLoS One 2016, 11(12):e0167560.

43. Gauthier B, Wane W: Bypassing health providers: the quest for better price and quality of health care in Chad. Social Science \& Medicine 2011, 73(4):540-549.

44. PMA2020: Performance Monitoring and Accountability 2020, PMA2014/DRC-Round 4: Key Family Planning Indicator Brief. In.: [Kinshasa School of Public Health and Tulane School of Public Health and Tropical Medicine], Baltimore, MD: PMA2020. Bill \& Melinda Gates Institute for Population and Reproductive Health, Johns Hopkins Bloomberg School of Public Health; 2018.

45. Akin JS, Hutchinson P: Health-care facility choice and the phenomenon of bypassing. Health Policy and Planning 1999, 14(2):135-151.

46. Yao J, Agadjanian V: Bypassing health facilities in rural Mozambique: spatial, institutional, and individual determinants. BMC health services research 2018, 18(1):1006.

47. Kante AM, Exavery A, Phillips J, Jackson E: Why women bypass front-line health facility services in pursuit of obstetric care provided elsewhere: a case study in three rural districts of Tanzania. Tropical Medicine \& International Health 2016, 21(4):504-514.

48. Kruk ME, Paczkowski M, Mbaruku G, De Pinho H, Galea S: Women's preferences for place of delivery in rural Tanzania: a population-based discrete choice experiment. American journal of public health 2009, 99(9):1666-1672. 
49. Hong R, Montana L, Mishra V: Family planning services quality as a determinant of use of IUD in Egypt. BMC Health services research 2006, 6(1):1.

50. Leonard KL, Mliga GR, Haile Mariam D: Bypassing health centres in Tanzania: revealed preferences for quality. Journal of African Economies 2002, 11(4):441-471.

51. Muanda MF, Ndongo GP, Messina LJ, Bertrand JT: Barriers to modern contraceptive use in rural areas in DRC. Culture, health \& sexuality 2017, 19(9):1011-1023.

52. Romaniuk A: Persistence of High Fertility in Tropical Africa: The Case of the Democratic Republic of the Congo. Population \& Development Review 2011, 37(1):1-28.

53. Abraha TH, Belay HS, Welay GM: Intentions on contraception use and its associated factors among postpartum women in Aksum town, Tigray region, northern Ethiopia: a community-based crosssectional study. Reproductive health 2018, 15(1):188.

54. Hong R, Montana L, Mishra V: Family planning services quality as a determinant of use of IUD in Egypt. BMC Health services research 2006, 6(1):79.

55. Seiber EE, Bertrand JT: Access as a factor in differential contraceptive use between Mayans and ladinos in Guatemala. Health Policy and Planning 2002, 17(2):167-177.

56. Donabedian A: The quality of care: how can it be assessed? Jama 1988, 260(12):1743-1748.

57. Cleland J, Harbison S, Shah IH: Unmet need for contraception: issues and challenges. Studies in family planning 2014, 45(2):105-122.

58. Westoff CF: Unmet Need for Modern Contraceptive Methods. DHS Analytical Studies No. 28. In. Calverton, Maryland, USA: ICF International.; 2012.

59. PMA2020: Performance Monitoring and Accountability 2020, PMA2014/DRC-Round 4: Key Family Planning Indicator Brief. In.: [Kinshasa School of Public Health and Tulane School of Public Health and Tropical Medicine], Baltimore, MD: PMA2020. Bill \& Melinda Gates Institute for Population and Reproductive Health, Johns Hopkins Bloomberg School of Public Health; 2016.

60. PMA2020: Performance Monitoring and Accountability 2020, PMA2014/DRC-Round 3: Key Family Planning Indicator Brief. In.: [Kinshasa School of Public Health and Tulane School of Public Health and Tropical Medicine], Baltimore, MD: PMA2020. Bill \& Melinda Gates Institute for Population and Reproductive Health, Johns Hopkins Bloomberg School of Public Health; 2015.

61. PMA2020: Performance Monitoring and Accountability 2020, PMA2014/DRC-Round 2: Key Family Planning Indicator Brief. In.: [Kinshasa School of Public Health and Tulane School of Public Health and Tropical Medicine], Baltimore, MD: PMA2020. Bill \& Melinda Gates Institute for Population and Reproductive Health, Johns Hopkins Bloomberg School of Public Health; 2014.

62. Kwete D, Binanga A, Mukaba T, Nemuandjare T, Mbadu MF, Kyungu M-T, Sutton P, Bertrand JT: Family planning in the Democratic Republic of the Congo: encouraging momentum, formidable challenges. Global Health: Science and Practice 2018, 6(1):40-54.

\section{Figures}




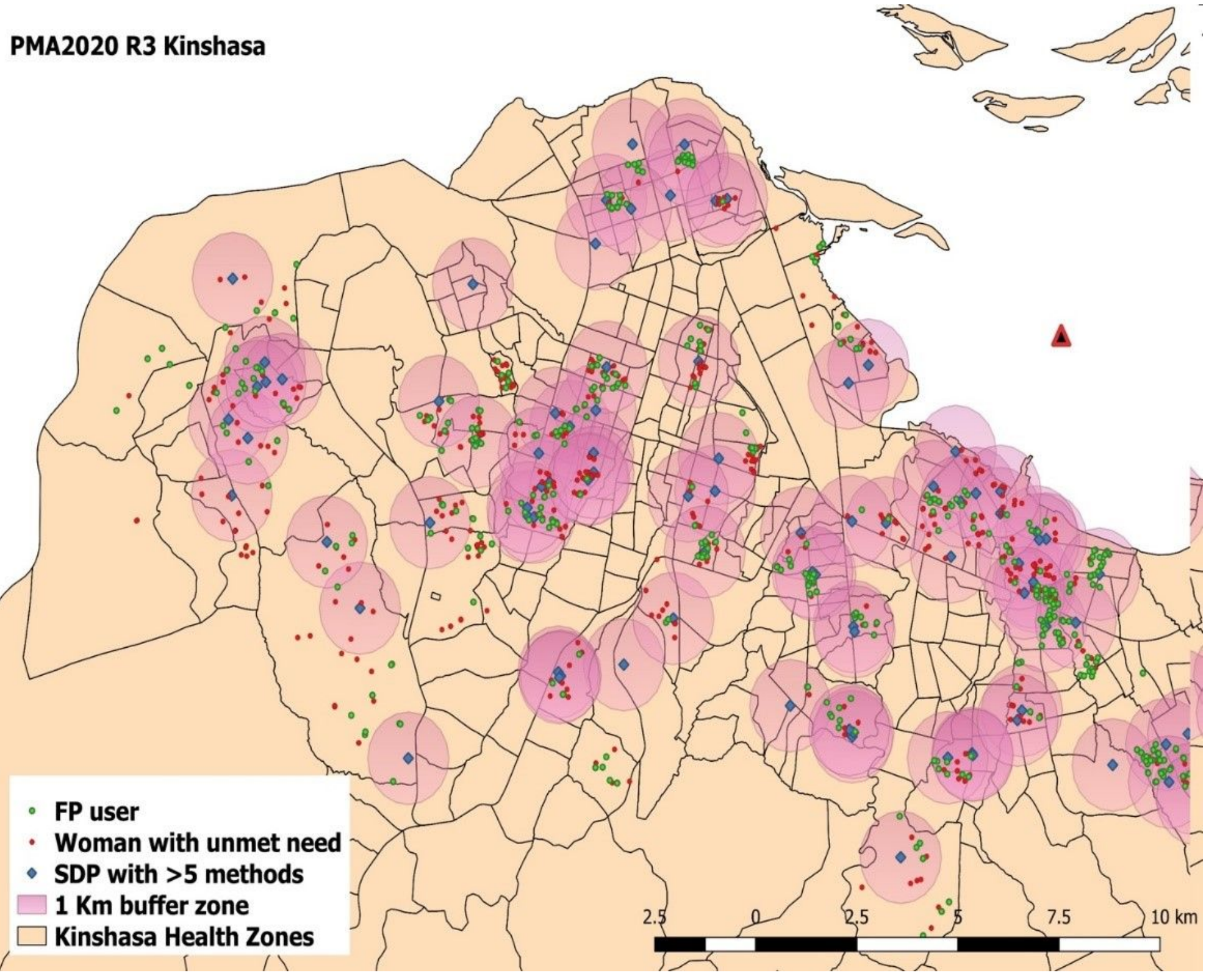

Figure 1

The map of the distribution of women in relation to SDPs with at least five methods, PMA2020 R3 Kinshasa 